\title{
Understanding the organization of sharing economy in agri-food systems: evidence from alternative food networks in Valencia
}

\author{
Isabel Miralles $^{1} \cdot$ Domenico Dentoni $^{1}{ }^{1} \cdot$ Stefano Pascucci $^{1,2}$
}

Accepted: 6 February 2017 / Published online: 15 March 2017

(C) The Author(s) 2017. This article is published with open access at Springerlink.com

\begin{abstract}
Despite the proliferation of sharing economy initiatives in agri-food systems, the recent literature has still not unravelled what sharing exactly entails from an organizational standpoint. In light of this knowledge gap, this study aims to understand which resources are shared, and how, in a heterogeneous set of sharing economy initiatives in the context of food and agriculture. Specifically, this study compares the organization of various forms of alternative food networks (AFNs), which are recognized to be frugal forms of sharing economy initiatives (i.e., locally based, small-scale and with limited use of information technology), in terms of leadership, bureaucracy, shared resources and participants' engagement. Data from a comparative case study across 18 AFNs identify five sharing economy models of AFNs with distinctive shared resources and organizational mechanisms: consumer groups; commercial community gardens; as well as network-based, privately owned and publicly owned self-consumption community gardens. These models also display notable differences in terms of their origins, participants' goals and constraints which, to some extent, may be associated to the nature of their organization. Findings inform policy-makers, AFNs' leaders and stakeholders-especially those seeking to support innovative models towards
\end{abstract}

Domenico Dentoni

domenico.dentoni@wur.nl

Isabel Miralles

isamiralles.share@gmail.com

Stefano Pascucci

stefano.pascucci@wur.nl

1 Management Studies Group, Wageningen University, Wageningen, The Netherlands

2 University of Exeter Business School, Exeter, UK sustainable transitions-on how to tailor institutional norms and develop networks to meet the heterogeneous needs of different typologies of sharing economy initiatives in agri-food systems.

Keywords Sharing economy · Organization theory · Consumer groups · Community gardens · Case study
Abbreviations
AFN Alternative Food Networks
AMAP Associations pour le Maintien de l'Agriculture
Paysanne
CSA Community supported agriculture
HCPC Hierarchical clustering on principal components
MCA Multiple correspondence analysis
SPG Solidarity purchasing group

\section{Introduction}

The concept of sharing economy is rising in the societal and academic debate. Although contested in terms of its multiple dimensions and frames (Belk 2007; Bardhi and Eckhardt 2012; Martin et al. 2015), the sharing economy generally refers to models of co-access and co-ownership of resources, goods and services for joint production and/ or consumption among multiple actors (Belk 2013) which involves a reduction of individual ownership (Botsman and Rogers 2010; Gansky 2011). Car or bike sharing programs, clothes swapping, tools sharing groups, accommodation exchanges, co-working spaces and renewable energy communities have been studied as rapidly growing examples of sharing economy initiatives worldwide (Sunrun 2013; Jurich 2013; Orsi 2013). Sharing economy has also been emerging and establishing within the agricultural 
and food (or agri-food) systems as well, generally in more frugal forms-i.e., locally based, in small scale and with limited use of information technology-relative to other economic sectors (Heinrichs 2013; Martin 2016). Although still remaining a niche if compared to the mainstream agricultural and food, sector these initiatives have significantly grown worldwide in the last decade (Goodman and Goodman 2009; Mount 2012; Si et al. 2015; Migliore et al. 2015; Forssell and Lankoski 2015). Commonly studied models of sharing economy in agri-food systems include community gardens (Cohen and Muñoz 2016; Hartl et al. 2016), food swapping (Schor et al. 2016), food consumer groups and networks (Martin 2016).

A critical point in this debate involves the role that the sharing economy will play in supporting social and economic actors towards sustainable transitions in future years (Sacks 2011; Contreras and Snir 2011; Standage 2013), both at a local and a global level and in agri-food systems. After an initial phase of enthusiasm, more critical voices have progressively risen too. On the one hand, experts argued that the sharing economy provides citizens with a more decentralized and small-scale provision of products and services (Gaskins and Stehfest 2010) and opportunities for investing in new ventures with limited resources (Smith 2014). Another argument, from a social and environmental point of view, supports that the sharing economy stimulates participation in groups; thus creating resilient communities (John 2013), as well as a way of designing consumption models that address climate change and natural resource scarcity problems (Heinrichs 2013). On the other hand, scholars have highlighted risks and adverse impacts that the sharing economy brings about. Risks include, amongst others, a shift towards poorly regulated markets, with consequent issues of taxation avoidance or erosion of labour and trade union rights (Gruzka 2015; Martin 2016), and the perpetuation of non-inclusive practices, for example generating corporate co-optation and socio-cultural exclusion (Richardson 2015; Schor et al. 2016).

Yet, this dialectics among contrasting perspectives on the societal impact of sharing economy initiatives still lacks a deeper understanding on how different organizational mechanisms may influence the nature and process of sharing (i.e. which resources are shared and how decisions are collectively taken to control them). This gap is particularly relevant when looking at the wide variety of initiatives taking place in agri-food systems, as frugal forms of sharing economy have potential to play important roles for the inclusion of a broader range of social and economic actors towards sustainable transitions (Heinrichs 2013; Martin 2016).

To contribute to this debate, this research takes an organization theory perspective to compare a heterogeneous set of sharing economy initiatives in agri-food systems.
In particular, this research builds upon three adjacent literature strands. The first strand includes comparative studies on sharing economy initiatives which do not focus on organizational mechanisms. These studies sought to compare sharing economy forms in terms of participants' characteristics and motivations (Cohen and Muñoz 2016; Barnes and Mattsson 2016) or the nature of the shared goods (Lamberton and Rose 2012). A second strand of studies has recently focused on organizational issues in the sharing economy, yet missing a comparative perspective. For example, Schor et al. (2016) described the informal mechanisms that perpetuate exclusion in food swapping, while Hartl et al. (2016) analysed participants' preferences for different organizational forms. A third strand of the literature has analysed how organizations coordinate actions or decisions to achieve collective outcomes, such as co-producing or co-consuming key tangible resources, for example in the context of open source software (O'Mahony and Ferraro 2007), communities (Jones et al. 1997; Bowles and Gintis 2002) and cooperatives and producer organizations (Ménard 2005, 2007). While this third strand provides theoretical insights into the functioning of organizations grounded on co-ownership or co-access to resources, this third strand has still not compared sharing economy initiatives. Taking stock from these works, in this study we seek to compare how heterogeneous organizational mechanisms influence the nature of sharing processes and, accordingly, face or overcome different organizational challenges.

To understand how organizational mechanisms influence sharing processes in a heterogeneous set of initiatives in agri-food systems, this study undertakes two subsequent steps of analysis with an inductive approach (Eisenhardt 1989). First, it develops empirical typologies of alternative food networks (AFNs) from the selected cases operating in the urban and peri-urban area of Valencia (Spain) through an open coding and clustering procedure (Gioia et al. 2013; see also section on methodology). As their name suggest, AFNs have developed as an alternative to corporate-centric and industrialised food sectors (Renting et al. 2003). Furthermore, AFNs are traditionally networks meant as sets of informal relationships among multiple actors although, similarly to other forms of sharing economy initiatives, over time their organization also entailed formal mechanisms (e.g. contracts, bylaws, formalized tasks) (Pascucci 2010; Migliore et al. 2014; Pascucci et al. 2016). Many forms of AFNs, but not all, represent examples of sharing economy initiatives (Cohen and Muñoz 2016; Hartl et al. 2016; Martin 2016; Schor et al. 2016) since they entail coownership and/or co-access to resources, goods and services for joint production and/or consumption. Other forms of AFNs, such as farmers' markets or short food supply chains (Wubben et al. 2013), do not involve co-ownership and/or co-access and therefore are not considered in this 
study as sharing economy initiatives. Moreover, the urban and peri-urban context of this study suits the urbanization trends that stimulated the emergence or design of neighbourhood-based sharing initiatives (Cohen and Muñoz 2016; McLaren and Agyeman 2015), transforming cities and urban contexts into platforms for resource sharing also in agri-food systems (Gansky 2011).

As the second and last step of analysis, this study interprets the empirical typologies of AFNs with the theoretical lens of organization theory (Grandori 1997; Adler 2001) applied to the context of the sharing economy (see next section about the conceptual framework). In particular, this lens helps the understanding of the heterogeneity of organizational mechanisms regulating the resource sharing among participants, the decision-making processes and the nature of the shared resources (e.g. natural, financial, physical, and social or human resources) in AFNs. Empirical findings from these two steps of analysis-also in light of the constraints that different organizational mechanisms are associated with-lead to implications for theory development in understanding sharing economy initiatives in agrifood systems (see section on implications for theory development) and recommendations for policy-makers and other AFNs's stakeholders (see final section).

\section{Conceptual framework}

\section{Debate on the key features of sharing economy initiatives}

The concept of the sharing economy, as well as the notion of sharing itself, has been subject to a wide range of interpretations. According to Belk $(2007,2010,2013)$ and Bardhi and Eckhardt (2012), the concept of sharing ranges from joint ownership of resources (e.g. gardens collectively owned by a group of individuals) to joint access to resources (e.g. car sharing). Co-ownership and coaccess differ from activities like gift giving or commodity exchange that involve transfer of ownership. In particular, Belk's definition as "the act and process of distributing what is ours to others for their use or vice versa, receiving something from others for our use" (Belk 2007, p. 126) reinforces the idea of sharing as co-access to resources. Debate on the notion of sharing has also exposed the key distinctive features of sharing economy initiatives to different interpretations (Botsman 2013; Coalition 2014; Gansky 2014; Lamberton and Rose 2012; Smith 2014). The recent literature has debated at least six key features pertaining to sharing economy initiatives:

1. Collaborative consumption. According to Botsman (2013), collaborative consumption refers to consum- ers' use of common goods and resources in activities like trading or renting. For example, consumers share knowledge prior to transfer of ownership of goods and services, such as eBay or Craigslist, mainly to save time or money and/or to contribute to better environmental practices (Botsman 2013; Schor 2014). In contrast with Botsman (2013), and in line with Belk's (2007) definition of sharing, other authors narrowed down collaborative consumption as the consumers' act of co-owning or co-accessing goods, such as cars or bikes, for a fee or other compensation (Bardhi and Eckhardt 2012; Lamberton and Rose 2012; Belk 2013).

2. Pooling of goods and services. According to John (2013), the pooled goods and services may be instrumental for shared production, such as in the case of Wikipedia or Linux, which are based on people pooling knowledge for both production and consumption purposes (John 2013). Alternatively, the pooling of goods and services may serve the purpose of shared consumption, as in the case of food swapping (Schor et al. 2016) or car sharing (Belk 2013). Moving beyond this dichotomy between production and consumption, other authors have recently described the pooling of goods and services as a continuum between co-production and co-consumption (Heinrichs 2013; Cohen and Muñoz 2016).

3. Distribution of Power. According to Botsman (2013), networks of individuals or communities experience more decentralized control over resources through sharing economy initiatives than through traditional government-centric or corporate-centric models. Yet, recent evidence shows that power issues, specifically dynamics of exclusion from co-access to resources, may still take place in subtle forms among participants in the sharing economy (Schor et al. 2016). Furthermore, the absence or scarcity of public regulation on many new forms of sharing economy may lead to cases of labour exploitation (Richardson 2015; Martin 2016), and thus, even more power inequality.

4. Small economic actors. According to Orsi (2013) and Gansky (2014), the sharing economy provides an opportunity for both individuals and micro or small enterprises to benefit from co-access and co-ownership of resources. While recognizing the potential for small economic actors to gain control over strategic resources through co-production or co-consumption, scholars have also noted that corporations may also gain control over sharing economy initiatives, co-opt and financially exploit them (Schor 2014; Gruszka 2016; Martin 2016). Therefore, the tension between predominance or co-existence between large and small actors in the sharing economy literature is still unresolved. 
5. Trust among the sharing participants. According to Orsi (2013) and Botsman (2013), one of the unique features of the sharing economy hinges on trust-based relationships among the sharing community. Whereas members may not know each other personally (Business Innovation Observatory EU 2013), the trust towards the sharing organization and its mechanisms facilitates the joint access or ownership of resources. Yet, scholars have recently distinguished between formal and informal rules to establish trust in sharing economy initiatives, and found that most participants support the presence of formal rules to enhance cooperation (Hartl et al. 2016).

6. Innovative and more efficient utilization of resources. According to Orsi (2013), sharing economy initiatives aim to redeploy underused or slack resources to create economic, social or environmental value. The recent debate revolved, though, around whether participants in sharing economy initiatives are driven by social or environmental values or instead by other functional goals (Schor 2014; Gruszka 2016). Looking across multiple models of collaborative consumption, for example, Barnes and Mattsson (2016) found that the efficient use of resources was a key driver for sharing participants mostly from a financial perspective, but rarely from an environmental perspective.

\section{Alternative food networks (AFNs) as sharing economy initiatives}

A large number of AFNs are recognized as examples of sharing economy initiatives in agri-food systems (Bloemmen et al. 2015; Del Corso et al. 2015), in particular fitting with the narrower definition of sharing as co-access or co-ownership of tangible resources (Belk 2007, 2010, 2013; Bardhi and Eckhardt 2012). Three commonly studied examples of AFNs exemplify the heterogeneity of sharing economy initiatives in agri-food systems: community supported agriculture (CSAs), Associations pour le Maintien de l'Agriculture Paysanne (AMAP) and solidarity purchasing groups (SPGs):

i. CSA refers to local farmers and consumers engaging with one another in a small-scale supply chains that connect them directly. Originally, and differently from similar sharing economy models in AFNs, CSA relied on the sharing of financial resources, as consumers pay a fee prior to their harvest and access to products. CSAs aim to increase farmers' financial security and partially protecting them from production risks (Cicia et al. 2011). Yet, the mechanisms and approaches of sharing in CSAs have evolved and became more multi-faceted over time, with a wide heterogeneity of distribution of access and decision-making rights among participants, resources shared at different stages of production, and the nature of the rules (formal versus informal) of sharing (Henderson and Van En 2007; Schnell 2007).

ii. AMAP are forms of sharing that widely engage both consumers and producers in decision-making processes around pricing, production sustainability and small-scale viability (Chiffoleau 2009; AMAP 2014). When investing their financial capital in AMAP at the start of a new harvest season, consumers negotiate both price and production features for the share, together with the farmer; thus fully embedding consumers into the production system (Dubuisson-Quellier et al. 2011; Urgenci 2013).

iii. Solidarity purchasing groups (SPGs) refer to groups of consumers jointly organized to buy goods directly from nearby producers in accordance with fair environmental practices and social justice (Migliore et al. 2015; Grasseni 2014; Colombo 2012). Relative to CSA or AMAP, participants in SPGs generally share funding and equipment to transport, store and distribute food from farm to the participants' kitchens (Brunori et al. 2012). Moreover, as consumers are the initiators of SPGs as opposed to CSA and AMAP, they also control most of the decisions on the product basket, production processes and prices (Brunori et al. 2012). Finally, SPGs traditionally share resources through close and trust-based relationships, as opposed to rules that formalize roles and rights among participants (Colombo 2012; Brunori et al. 2012). Beyond these three examples, other recently considered examples of AFNs recognized as sharing economy initiatives in agri-food systems also include community gardens (Cohen and Muñoz 2016; Hartl et al. 2016), food swapping (Schor et al. 2016), consumer groups and networks (Martin 2016).

In these different forms of AFNs, participants co-access or co-owned tangible resources such as land, water, money, food, and agricultural equipment to a certain extent (Pascucci et al. 2013), thus fitting with Belk's definition of sharing (2007). As in the broader debate on sharing economy initiatives, also these examples of AFNs could be described as a continuum from shared production to consumption (Cohen and Muñoz 2016). Furthermore, these AFNs have so far only participated by small economic actors and overall they rely on trust among the sharing participants, thus supporting the views of Orsi (2013) and Gansky (2014) on their potential for an innovative redistribution of resources in the economy. Still, the organizational mechanisms that drive the sharing in the different forms of AFNs are diverse and unexplored. This requires an organization theory lens to understand and explain their heterogeneity. 


\section{Organization theory perspectives on processes of sharing}

Although outside of debate on sharing economy initiatives, previous studies in the organization theory domain focused on how organizations manage and coordinate actions to achieve collective outcomes (Grandori 1997; Adler 2001). This literature is relevant both for coordinated actions that are taking place among individuals (Adler 2001) and among organizations, such as in inter-firm collaborations and networks (Grandori 1997; Grandori and Furnari 2008). As such, this literature provides a useful interpretative lens to describe the mechanisms that drive co-production or coconsumption meant as the sharing of ownership and access to tangible resources.

This strand of organization theory emphasized the relevance of balancing elements of authority (or leadership) and bureaucracy (i.e. formal codes and rules) with community (i.e., trust-based) and democratic elements (O'Mahony and Ferraro 2007). According to how these organizational elements are combined, sharing resources in communities of production or consumption (such as AFNs) may vary in terms of intensity (i.e., more or less resources are shared) and practices. In particular, co-ownership or co-access to resources revolves around the tension of ensuring the right level of control, via authority and formalized norms, without limiting the ability of community members to participate and benefit from the shared resources (O'Mahony and Ferraro 2007). As a consequence, organizations such as AFNs have the tendency to rely on hybrid forms of governance in which participants are pooling resources and sharing associated decisions and property rights while remaining independent on non-shared assets (Ménard 1996, 2005). Actors participating in organizations with hybrid forms face a number of hazards due to the difficulties in clearly defining rules on shared resources (i.e. how to share benefits and control opportunism), as well as how to adapt to uncertain and continuously changing environments (Ménard 2005). Control, adaptation and safeguards in these communities are instilled and regulated by forms of authority and bureaucratic procedures (Adler and Heckscher 2006) under the continuous scrutiny of participatory (democratic) decision making processes, and relational (trust-based) contracting (O'Mahony and Ferraro 2007). The combination of communitarian and democratic elements with formal and codified authority define types of leadership which are often based on collectively recognized merits, status and/or abilities (O'Mahony and Ferraro 2007). Therefore, the concept of authority (or leadership) helps to understand organizational diversity in sharing communities as AFNs. At the same time, since participation is regulated by membership rules, it is also important to identify the level of formalization attached to it, thus how bureaucratic procedures may influence democratic decision-making processes in AFNs. This aspect is reflected in whether communities in AFNs maintain a relatively open- and less formalized approach to participation, thus acting as a network, or otherwise regulate it formally via membership.

Taking stocks from these organization theory perspectives, this study interprets the differences among sharing economy initiatives in agri-food systems in terms of leadership, bureaucracy, shared resources and participants' engagement. These attributes are considered as the key organizational elements to understand the heterogeneity of AFNs (Wubben et al. 2013) and to relate the organization of sharing economy initiatives to their potential constraints for their development and societal impact.

\section{Methods}

This study follows an inductive research approach (Eisenhardt 1989) performed in two steps to understand the heterogeneity of sharing economy initiatives from an organizational theory perspective. As a first step the study identifies multiple AFNs in urban and peri-urban Valencia as a suitable setting (Yin 2009) to empirically describe the heterogeneity of AFNs as sharing economy initiatives in agri-food systems, an open coding and clustering procedure (Gioia et al. 2013) enables us to identify the main empirical commonalities and differences among the sampled AFNs (see results in section on Empirical typologies of Alternative Food Networks in Valencia). The second step of the analysis involves interpreting the empirical typologies with the lens of organization theory and relating them with their key organizational constraints.

\section{Case selection}

This research identifies multiple AFNs in the urban and peri-urban area of Valencia, Spain as a purposive sample (Yin 2009) that mirrors the heterogeneity of sharing economy initiative features in the context of agri-food systems. Therefore, the main inclusion criterion was the fit with Belk (2007)'s definition of sharing and-to the extent that agri-food systems would allow-the display heterogeneity of the key features of sharing economy initiatives identified in the literature. Following Yin's (2009) principle of purposive sampling, the second selection criterion was the likelihood that the selected cases displayed a variety of organizational characteristics to achieve the research aim of developing typologies of sharing economy initiatives from an organization theory perspective. Finally, the research continued the process of case selection to reach theoretical saturation (Eisenhardt 1989), meaning until the point that 
the likelihood of finding new relevant elements for the purpose of the study in an additional sample was low.

Based on these inclusion criteria, 39 cases were found (of which 20 were consumer groups and 19 community gardens) in urban and peri-urban Valencia through a review of the academic and grey literature and snowball sampling. Finally, data was obtained from a total of 18 cases, including 6 consumer groups and 12 community gardens, as the remaining groups either did not respond or declined to participate. Thus, consumer groups are slightly underrepresented relative to the overall population of AFNs in Valencia. Consistently with the inclusion criteria, these cases all fit with Belk's definition of sharing (2007), yet with notable differences in many of their features as sharing economy initiatives. First, collaborative consumption elements were identified in the 6 consumer groups as they collectively organize to perform the ordering of food products as well as the distribution and purchase. In contrast, for the 12 community gardens the collective production of food was the main joint activity undertaken in all the investigated cases. Second, the differences between co-consumption and co-production in the sample were also reflected in the differences in the nature of pooled goods and services across the sampled AFNs (e.g., land, water, food, money, agricultural equipment, etc.). Third, the sample varied in their use of trust among sharing participants (although trust overall plays an important role in all AFNs), as the AFNs took different approaches to joint management and decision-making. Fourth, distribution of power also varied significantly across AFNs. The sharing process were dominated by few participants (e.g., owners of the co-accessed land, or few representatives with decision-making tasks) in some community gardens, while in most consumer groups decisionmaking and control over the shared resources was widely distributed. Fifth, all the sampled AFNs consisted of small economic actors, consistently with the key features of sharing economy initiatives in agri-food systems. Finally, our sample selection and analysis did not assess differences in innovative and more efficient utilization of resources, as exploring the motivation and outcomes of AFNs (Cembalo et al. 2015) as an example of sharing economy initiatives was beyond the scope of this study.

\section{Data collection and analysis}

The empirical research was performed through semi-structured interviews in March and April of 2014. Interviews were designed with semi-structured questions aimed at eliciting responses from participants which might shed light on the organizational elements of the AFNs and thus enabling an understanding of their heterogeneity. Depending on the structure of the sampled AFNs, interviewees included gardeners, landowners, group members and group initiators. In
11 out of 18 cases, data was collected from multiple primary sources within the AFN and, when this was impossible, data was triangulated with secondary sources (e.g., written AFN rules, websites, blogs, leaflets and grey literature). To further enrich the data collection, AFNs' site and participant observation took place in 16 out of 18 cases. Consistently with the adopted organization theory perspective, interviews included four sets of questions concerning: the origin of the initiatives; the availability of resources and their co-ownership or co-access status; the type of relationships among the involved participants and their decisionmaking processes; and the main constraints affecting the development of the AFNs. Data derived from interviewers' observations, archival data and field notes was triangulated with the transcripts from the interview records to ensure the reliability of the interpretation (Eisenhardt 1989; Yin 2009).

Consistently with the inductive nature of the research (Eisenhardt 1989), the data analysis took place in two steps. First, an open coding was driven by the empirical data, that is, without any prior assumption related to the extant theory. Second, these open codes were interpreted according to the selected theoretical lenses (Gioia et al. 2013) of organization theory. The first step of open coding entailed both a within-case and a cross-case technique. Coding the 18 interview transcripts and archival data allowed identifying the organizational elements characterizing each case; reaching a total of 68 variables organized in seven empirical categories (Table 3 in Appendix). Coding entails a process of extracting, comparing and modifying the concepts as new data emerges (Gioia et al. 2013). Furthermore, it highlights recurrent patterns to further develop typologies of cases with similar elements.

Based on the open coding, a multiple correspondence analysis (MCA) was conducted to graphically visualize the differences emerging empirically across the selected cases. MCA allows identifying the key components that explain the differences among the 68 coded categorical variables (Table 3 in Appendix): the first component retains the maximum explained variance among the coded variables, the second the second largest variance, and so on (Husson et al. 2010). Based on this analysis, the first three components explain $56.46 \%$ of the variance of the system, while the first nine components explain $88 \%$ of the variance the system. Therefore the analysis only includes the information of the variables that were present on each of the selected axis of the MCA. ${ }^{1}$ Subsequently, a Hierarchical Clustering on Principal Components (HCPC) was implemented to

\footnotetext{
${ }^{1}$ Experts have stressed not to use the last axis of the MCA-considered as noise - as it can result in a decreased clustering stability (Husson et al. 2010).
} 
Table 1 Resource sharing stages along the food chain in consumer groups (diagonal grey lines), self-consumption community gardens (dark grey) and commercial community gardens (vertical grey lines)

\begin{tabular}{|c|c|c|c|c|}
\hline Stages $\rightarrow$ & Production & Distribution & $\begin{array}{l}\text { Purchase } \\
\text { (or sale) }\end{array}$ & Consumption \\
\hline \multicolumn{5}{|l|}{ Resources: } \\
\hline \multicolumn{5}{|l|}{ Food } \\
\hline \multicolumn{5}{|l|}{ Natural capital: } \\
\hline \multicolumn{5}{|l|}{ - Land } \\
\hline \multicolumn{5}{|l|}{ - Water } \\
\hline \multicolumn{5}{|l|}{ Human capital: } \\
\hline \multicolumn{5}{|l|}{ - Labour } \\
\hline \multicolumn{5}{|l|}{ - Information } \\
\hline \multicolumn{5}{|l|}{ - Agricultural knowledge } \\
\hline \multicolumn{5}{|l|}{ - Coordination skills } \\
\hline \multicolumn{5}{|l|}{ Physical capital: } \\
\hline \multicolumn{5}{|l|}{ - Production assets } \\
\hline \multicolumn{5}{|l|}{$\begin{array}{l}\text { - Storage/Distribution/ } \\
\text { Purchase space }\end{array}$} \\
\hline \multicolumn{5}{|l|}{ - Technology } \\
\hline \multicolumn{5}{|l|}{ Financial capital: } \\
\hline \multicolumn{5}{|l|}{ - Investments } \\
\hline \multicolumn{5}{|l|}{ - External funding } \\
\hline \multicolumn{5}{|l|}{ Social capital: } \\
\hline \multicolumn{5}{|l|}{ - Training } \\
\hline \multicolumn{5}{|l|}{ - Social events } \\
\hline - External support & & & & \\
\hline
\end{tabular}

The white cells stand for no shared resources and the light grey cells for unavailable information

group the selected cases into clusters according to the main components obtained from the MCA (for an extensive discussion on HCPC, see Husson et al. 2010). The HCPC requires that a distance and agglomeration criterion to be first defined: in this analysis the clusters were joined using a metric matrix distance (distance between pairs of observations) and binding criteria (distance between sets of observations) (Husson et al. 2010). The matrix distance was calculated using the Euclidean distance and the agglomeration criteria used was Ward's criterion, which minimizes within cluster variance. The hierarchy was represented by a tree called dendrogram which is indexed by the gain of within-inertia (Fig. 2). Finally, to learn more about the variables that characterize the partition of clusters, a $\chi^{2}$-test was run. All the statistical analyses were performed with the "FactoMineR" package in the statistical program "R" version 3.1.1 (Husson et al. 2013).

The second step of analysis was to interpret the open codes with the theoretical lenses of organization theory, consistently with Gioia et al. (2013) coding process. This entailed a second round of cross-case comparison of the empirical data between pairs of cases based on patterns of organizational assessment from theoretical assumptions. This resulted on a template of seven relevant 


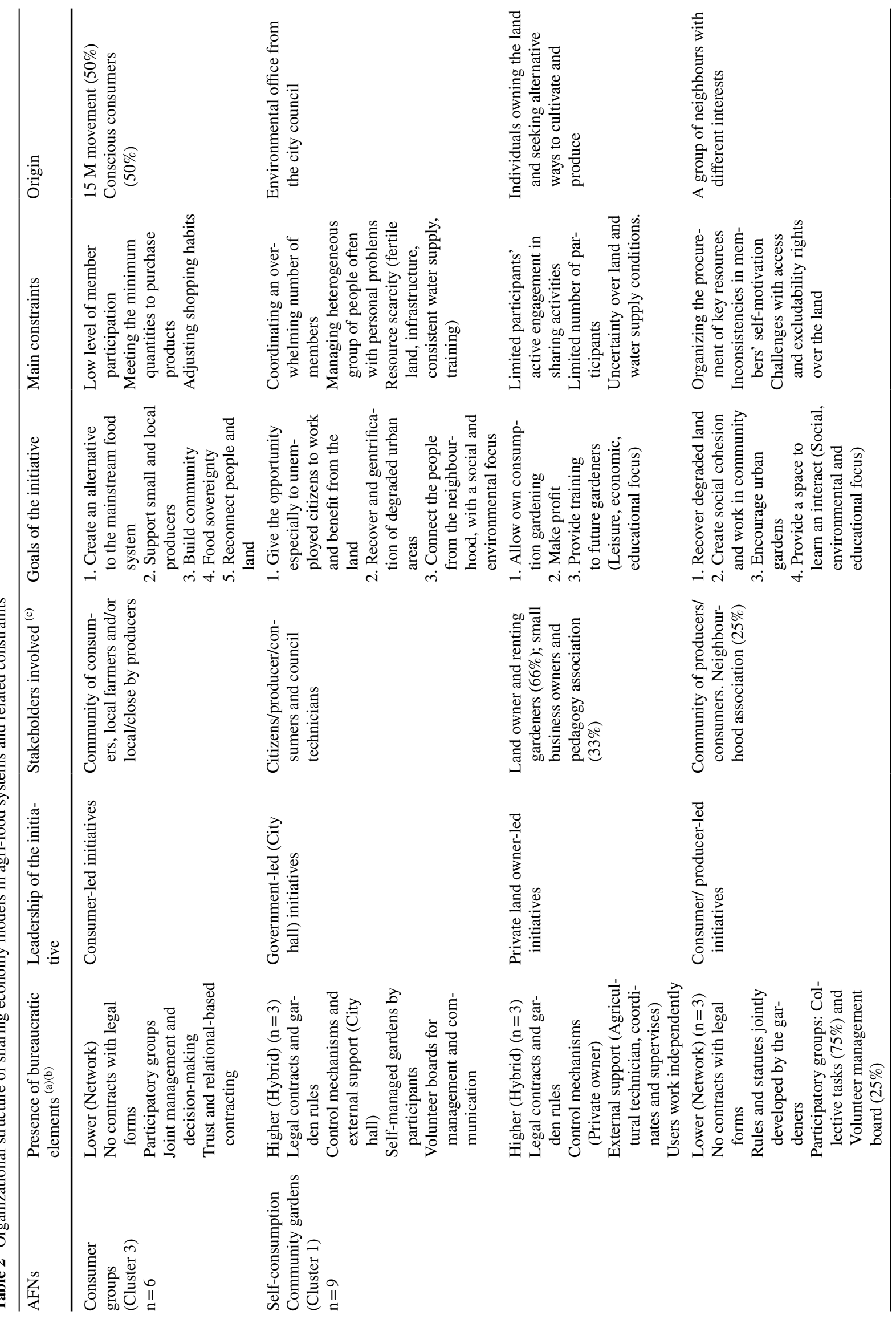


categories highlighting the major differences across the 18 cases according to their organizational structures: shared resources, level of bureaucracy, leadership of the initiative, participants' engagement, goals, constraints and origins. Tables 1 and 2 present the results of this second round of theory-driven analysis according to the seven categories identified.

\section{Empirical findings}

\section{Empirical typologies of alternative food networks in Valencia}

Based on the first step of open coding, Fig. 1 provides a visual differentiation of the studied AFNs according to the dimensions 1 and 2 of the MCA. The first two dimensions of this space are plotted to examine how similarities and differences between cases lead to different clusters. Three clusters, outlined by the coloured circles, arose among the sampled AFN. The top-right quadrant of the plot shows that the cases La Mateta de Fenoll, Tramuntana, Per L'horta, Algirós, Patraix and El cabasset d'Arrancapins have strong similarities. Proceeding clockwise, the initiatives Terra i Canya, L'aixda com Eixida and L'hort del Carme can be clustered together. Last, the bottom-left and top-left quadrants show a similarity among the rest of the cases.

In a complementary fashion, results from the HCPC explain the key features that discern the three emerging clusters of AFNs (Fig. 2). The outcomes show the characteristics defining each cluster and the six most influential variables for this categorization, which are: "collective production", "collective purchase", "distribution of decision rights", "participatory certification", "market transactions" and "own consumption". Based on their distinctive characteristics, we labelled the three clusters as "Self-consumption community gardens" for cluster 1, "Commercial community gardens" for cluster 2 and "Consumer groups" for cluster 3 (Fig. 2).

Cluster 1 includes those community gardens where the food is produced exclusively for own consumption (therefore named "self-consumption community gardens"). These community gardens are characterized by lack of market transactions. First, this cluster of AFNs produces food for private consumption only, unlike the other two clusters where food exchange is a fundamental reason for the group establishment. As an outcome, AFNs in cluster 1 do not require a certification process, food transactions, orders or deliveries nor a space for distribution or purchase since production and consumption are limited to personal use. In contrast, the other two clusters do benefit from a certification process, although certification remains voluntary and informal. Second, a large percentage of the AFNs in this cluster count with 


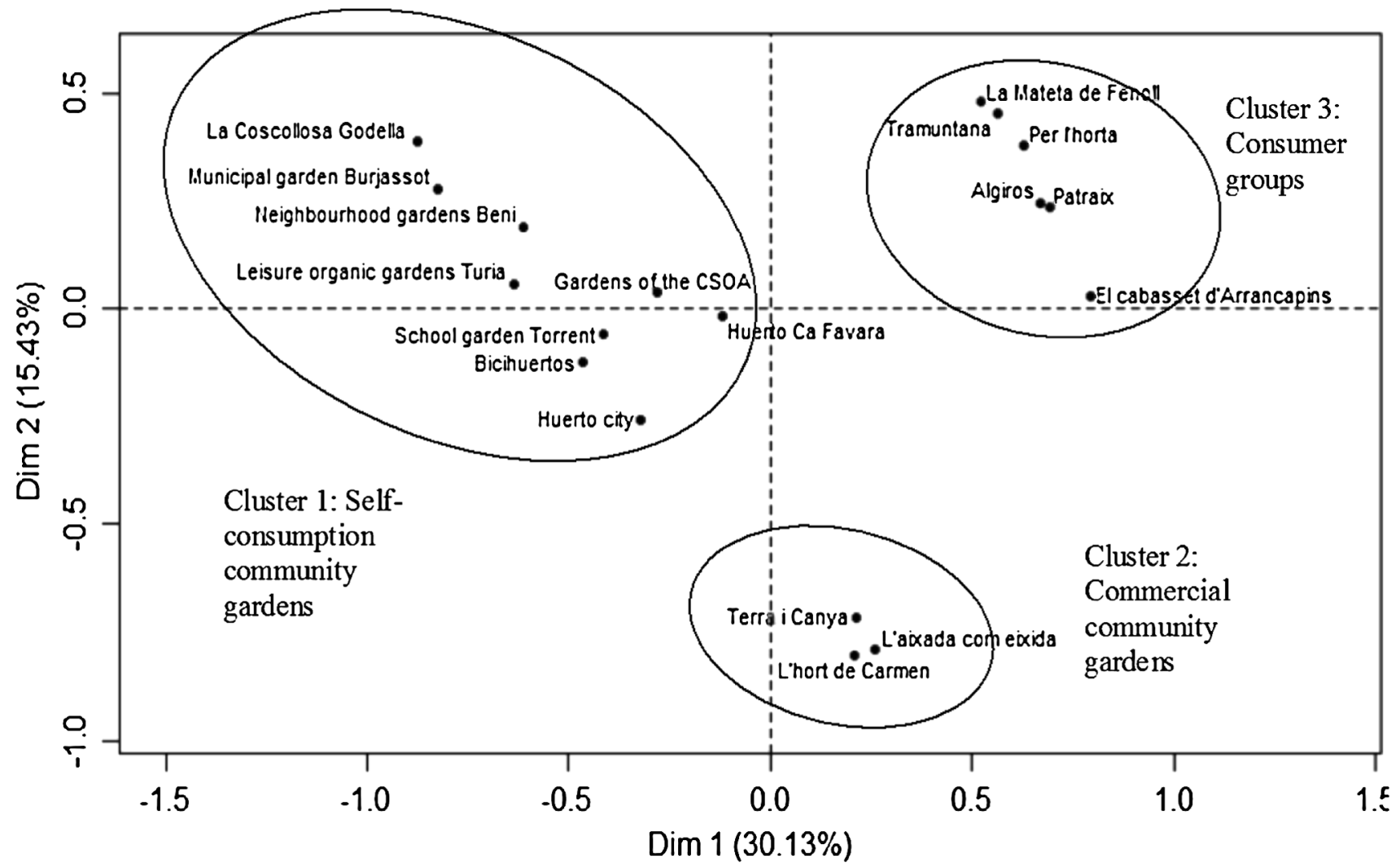

Fig. 1 Representation of the sampled cases on a map induced by the first two principal components of the MCA. Cluster 1 is circled in light grey, Cluster 2 in dark grey, and Cluster 3 in white

Fig. 2 Hierarchical classification on the principal components (HCPC) describing the similarity between community gardens and consumer groups. The boxes with numbers indicate each cluster

\section{Hierarchical Clustering}

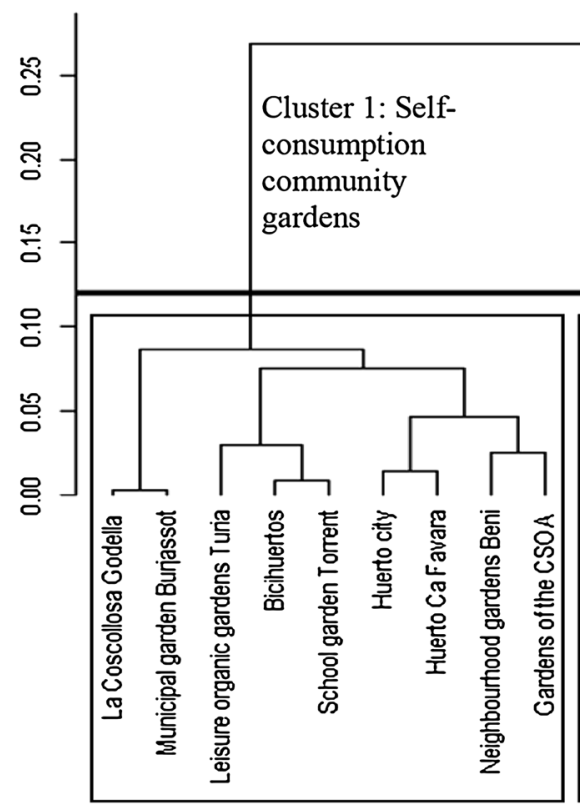

1

\section{Commercial} community gardens

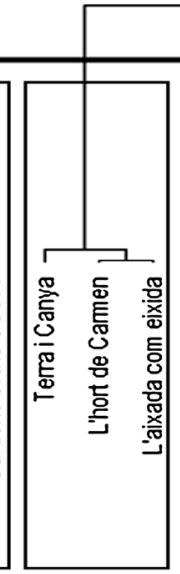

2

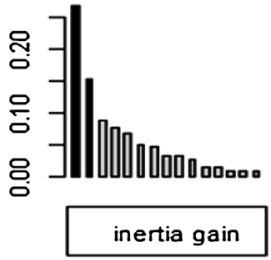

Cluster 3:

Consumer groups

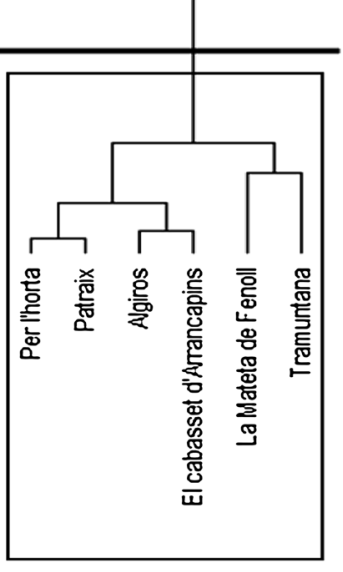

3 
external support for the coordination of the gardens. In other words, an external party such as the landowner or the city hall are involved in management and decision making processes. Third, these AFNs have formal practices which control members' participation. Yet, the members of the group collectively participate in the production process and take decisions on product portfolio or quality, amongst other production decisions. Finally, the sharing of natural resources such as land and water and the participation in training are key characteristics of this cluster of AFNs.

Cluster 2 includes community gardens based on commercial food transactions for livelihood (therefore named commercial community gardens). First of all, this cluster is strongly associated to gardeners that have no control on the distribution channels to deliver produce to consumers. Contrary to initiatives in own consumption community gardens and consumer groups which hold this decision right. For instance, members of the AFNs in this cluster do not have decision-making power on the logistics of the distribution or the delivery times, but are consumers who take this responsibility. Nevertheless, as a second feature of the cluster, a close relationship is likely to occur between producers and consumers involved in these groups. In fact, distinctive practices of this cluster of AFNs include product quality feedback and direct visits from consumers to producers. Third, the email is recognized as the primary communication channel for the market transactions. Last, the producers in this cluster are characterized for pooling money collectively for the maintenance or development of their initiative.

Cluster 3 is composed of six consumer groups. They are characterised by performing collective purchase of products but not undertaking food production activities, therefore having no decision rights over production portfolios. In addition, the consumer groups do not pool natural resources such as land or water, but generally present a common space for the distribution and purchase of food. A key factor that differentiates consumer groups from the other clusters is the timing of collective participation. Community gardens pool resources during food production as opposed to consumer groups where it is most prevalent during food ordering and purchasing.

\section{Resource sharing differences across alternative food networks in Valencia}

Using the lens of organization theory (O'Mahony and Ferraro 2007), differences across the three clusters of AFNs can be further articulated in terms of the nature of the shared resources (natural, human, physical, financial and social capital). The sharing of these resources differs along the several stages of the process including the procurement of agricultural inputs, food production, distribution, purchase (or sale) and consumption (Table 1). The commercial community gardens (cluster 2) are the AFNs with the highest levels of resource sharing, followed by selfconsumption community gardens (cluster 1) and consumer groups (cluster 3). Furthermore, commercial community gardens have the greatest range of sharing activities as they share all kinds of resource types from natural, human, physical, financial and social. Conversely, consumer groups share only human and physical capital. Self-consumption community gardens share their resources mainly at the production stage while consumer groups mostly pool resources at the distribution and purchase stages.

First of all, commercial community gardens (cluster 2) are characterized by the sharing of human and social capital. This reflects the wide variety of skills that members bring into the organization. Second, natural capital (land and water) are pooled along the complete food chain as various activities such as pick up points, lunch reunions or other events happen at the production site. Third, production assets and technology are key resources shared in these organizations. Last, they are the only models where money is pooled among members to invest in other shared resources.

Self-consumption community gardens (cluster 1) share fewer resources than cluster 2, yet the extent of sharing is equal at the production stage. Most of the self-consumption community gardens have their land divided into several plots and assigned to their group members for food production. The plots are generally cultivated by an individual or a group of people and always with a non-commercial purpose. Accordingly, the initiatives in this cluster present limited shared resources at the distribution stage and none at the time of purchase. Furthermore, coordination skills and training activities are generally shared among members, while social events and financial investments are not.

Lastly, consumer groups (cluster 3) do not participate in the production stage at any level and thus they do not share any natural resources. As a group, they do not focus on the exchange of information or agricultural knowledge as the group members often lack the time to organize or participate in group events or trainings. However, despite receiving no external support, consumer groups invest labour in managing the purchase and distribution of food to the ideals and needs of the group. They are also the only cluster focused on the development and use of common technology to organize shopping.

\section{Organizational mechanisms and barriers of alternative food networks in Valencia}

The theoretical lens of organization theory allows for further classification of the AFNs on the basis of six distinctive elements: presence of bureaucratic elements, 
leadership of the initiative, participants engaged, goals of the initiative, main constraints and origin. The application of this theoretical lens shows that, within the cluster of selfconsumption community gardens (cluster 1 ), further differences emerged in a three distinctive sub-typologies based on the use of bureaucracy and authority (Table 2): networkbased organizations (with lower levels of bureaucracy and distributed leadership), hybrid forms controlled by a private owner and hybrid forms controlled by a city hall (both having higher levels of bureaucracy and more concentrated leadership). Distinctions among these theory-driven clusters are summarized as follows.

\section{Consumer groups}

Consumer groups (cluster 3) are mainly governed with low levels of bureaucracy, meaning that relationships among participants are generally informal (Table 2). No contracts with legal status, but only norms of trust bind participants in a commitment to participate. To ensure the functioning of the group, management decisions are taken collectively. Similarities in values and ideologies among the group members facilitate consensus and conflict-free decision-making. The following common goals smooth the collective decision-making processes: (a) to provide an alternative to the mainstream food system by supporting local economies; (b) to gain knowledge on the food origin and production systems by getting closer to the production chain; and (c) to strengthen the local community. The organization and goals of these consumer groups reflect their origins. Half of these groups have roots in conscious consumers seeking organic and local production, while the other half are networks of activists inspired from the $15 \mathrm{M}$ Movement (Borge-Holthoefer et al. 2014). The 15 M movement was organized under the slogan "We are not commodities in the hands of bankers and politicians" through internet-based social networks. $15 \mathrm{M}$ participants were citizens independent from political parties and other established civil society organizations.

First of all, a major barrier of consumer groups is the low level of member participation, hindering performance of the group tasks to purchase and distribute food. Consumer groups have some active members that enable the steady functioning of the group, but most members' availability to participate in group activities remains low. The contact between the members of the consumer group is reduced at the time of pickup of food, which usually happens once or twice a week. Within this scenario, groups tend to experience difficulties in finding certain supplies or suppliers that align with their values; to engage new members or to participate in food-related activities. For example, some of the AFNs mentioned that it was complicated to find fruit producers because the fruit is not growing close by. To date they are not getting fruit because attempts to find producers have failed. It is often challenging to find close suppliers that meet the groups' criteria. Other consumer groups find it important to contact food and agricultural experts to bring a social component to the group; however this may not happen often due to the time constraints. Most of the consumer groups are willing to engage new members to their groups with motivation and time, yet, they have no time to coordinate a campaign to reach people in the neighbourhood. In the consumer groups, the levels of participation and commitment to the group are limited to the ordering and distribution of products.

Second, a significant barrier concerning the consumer groups relates to the purchasing of products and meeting the minimum quantities to perform these transactions. Based on the group members' values and needs, they set different agreements with the suppliers regarding the frequency of buying and the minimum order quantities. For example, one of the consumer groups has an agreement with a supplier that sells the oil in $20 \mathrm{~L}$ cans and until now they do not have enough people to reach that quantity, so they cannot order. Similarly, this group only consumes meat when they reach enough demand to sacrifice a lamb from the supplier. The conditions are mostly dependent on the group shopping power, which many members see as the biggest challenge. According to others, the hardest task is to maintain consistency on the products orders, as the consumer group may consume little or slowly. This leads to situations where consumer groups may not have enough volume to demand all the products they would like.

Finally, consumer groups are challenged to reach an adjustment of the shopping habits. The times to order each product vary and it is not always possible to buy certain products. In most of the consumer groups, fruit and vegetables can be ordered weekly but perishable products have different ordering times. For example in one of the groups, legumes are ordered every three months and other products, such as coffee, twice a year. As a result, more organization is needed to make sure that the stored food is sufficient until the next order. Other groups have different models, for example, members can only buy fresh produce in a closed box model. Typically this consists of a box of seasonal vegetables that varies throughout the farming season. This shopping approach involves a significant change from the supermarket model where you can choose the product you want and in the desired amounts. Consequently, it is often costly for some members of the consumer groups to adjust their shopping behaviour.

\section{Commercial community gardens}

Commercial community gardens (cluster 2) are also characterized by low presence of bureaucratic elements, thus 
resembling a network of informal relationships (Table 2). Informal structures for joint decision-making and resource sharing coordinate these commercial community gardens. Though, differently from consumer groups; decision-making lies exclusively with producers. Relative to consumer groups, commercial community gardens are less driven towards political meanings, yet still seek alternative and financially viable ways of promoting local production through direct relationships with consumers. The founders and leaders of these gardens are often a few entrepreneurial individuals who have catalysed the attention or interest of other participants through their social media, local food fairs or agro-ecology courses held by non-governmental organizations.

Given the nature of the shared resources and their organizational mechanisms, commercial community gardens face notably different barriers from consumer groups. First of all, individual participants find it a challenge to coordinate their time to engage in production, marketing and consumer awareness-raising activities. Since most of their time is dedicated to growing activities, participants constantly feel that they cannot focus on establishing relationships and more stable transactions with consumers. Given this constraint, participants complain that consumers do not sufficiently appreciate the value of their products. For example, regular customers are becoming reluctant to use the close box scheme based on a fixed amount of fresh seasonal vegetables. Moreover, many consumers lack awareness and culture and do not understand the value of gardens' products, where they come from, how they are produced and the overall story behind them. One sampled AFN developed a social media platform to create a stronger bond with consumers, yet participants find it challenging to constantly update and promote it over time.

As they manage a complex set of activities ranging from production to marketing, commercial community gardens also face issues of limited participation to sharing activities. Since their time is mostly absorbed in gardening, members lack time to diversify in activities. In two sampled AFNs there is excess land that members have no time to grow. Some available time could be used to produce and distribute key inputs more efficiently throughout the group, such as composting. Orchards could be re-organized to save water and energy, but members struggle to find time to invest collectively. Finally, accounting is an area where usually groups lack expertise. Often external collaboration works through food for time spent helping picking, although these have more the nature of social events rather than a focus on agricultural efficiency. The innovative ideas of a few individuals in the groups usually help overcoming this barrier: in one sampled AFN, for example, two members lead a crowdfunding project that funded the purchase of collective goods such as a van and a tiller.
Finally, commercial community gardens suffer the misfit of the legal framework for their type of organization. Registering as an association or as self-employment is often a duty that the group cannot afford. Yet, this paperwork is essential to insure the group activities, secure the workers' rights and the right to use the land. As a consequence, the commercial community gardens are not insured for situations that may damage the field, work accidents or claims for damage caused to third parties. In this scenario, if some accident happens, group members are subject to risks and their consequences. Similarly, in these groups, land and water are usually assigned based on trust, which of course prevents significant investments in it but at a high potential cost of not having any right. Nevertheless, the findings show an interest from the commercial community gardens to overcome this barrier. For example, one group, without any legal record to date, is trying to get the official documentation that would guarantee their right to use the land.

\section{Self-consumption community gardens}

Using an organization theory lens, self-consumption community gardens (cluster 1) can be further discerned in three sub-typologies. These three sub-groups present different levels of bureaucratic elements: one of the sub-groups displays lower levels of bureaucracy (i.e. is network model) and the other two sub-groups have higher levels (i.e. hybrid governance) (Table 2). Sub-groups with hybrid governance combine formal mechanisms (i.e., legal contracts, garden rules and control bodies for the correct functioning of the diverse approaches) and informal mechanisms (i.e., gardeners with enough independence to manage the field, getting organized through networks to perform common activities and decide on the "food portfolio", etc.). The combination of formal and informal features, together with suitable communication channels, stimulates frequent relationships among partners. These two sub-groups with hybrid governance differ based on the agents leading these organizations: one is led by government institutions (city hall), while the other is initiated by small private landowners. These subtypologies have notable differences in their goals, origins and organizational barriers.

First of all, government-led initiatives aim for a social and environmental improvement of the neighbourhoods where the gardens are located. In these initiatives, often born under the Agenda 21 auspices (Llamas-Sanchez et al. 2013), the municipality set different criteria for selecting the participants. In some of them, participants were recruited among various pre-existing (cultural, school or solidarity) associations. In others, unemployment or low income was a key criterion for selection. These organizations struggle to coordinate effectively due to the magnitude of these AFNs, which in some cases reach 300 members, and face 
resources and competence constraints. First, coordinating an overwhelming number of members generates bottlenecks in forming and managing boards of representatives, as well as enforcing their decisions. Enforcement is a sensible issue as members do not always respect the collective decisions, and the board has no power to impose rules, nor rewards or punishments. For example, in two groups, the board has established turns for members to clean common areas in the garden, as well as a prohibition on using synthetic fertilizers, but some members do not respect these decisions. Second, these AFNs are constituted by a very heterogeneous group of people. The participants are often selected by government authorities because of unemployment status or financial problems. This leads to AFNs with a large share of its members having limited experience in collaborating as an organization. Despite the large number of participants in AFNs, some major resources are scarce, including basic infrastructure, expertise from technicians and agricultural training on what and how to plant or on how to make compost. At the root of this resource scarcity, there are ownership problems. Members receive land and water from the city hall; however, they also need complementary resources that the city hall cannot provide consistently. At the same time, members feel ownership over the land that they use to grow their food, despite that it has only been temporarily borrowed for its use. This creates a negative impact on their participation because they do not perceive risks of having that land removed, according to some interviewed members.

Second, privately owned initiatives are more focused on financial benefits collected from rentals of land (plots) and most include an educational component. The founders are mostly land owners seeking a better use of their resources: some of them set up the initiative when they retired from their job, while others shifted towards a community-based model when finding that their agricultural production was not profitable enough. These organizations face the opposite problem to government-led initiatives. They generally have low levels of participation both in numbers and level of member involvement. Members often have jobs and families in the city so they struggle to devote sufficient time to grow food. At the same time, some groups have experienced tensions between members and supporting gardeners: since the land is rented from a private, some members felt entitled to constantly receive support from gardeners, who instead are available only for a limited time. This challenge arises also because of discussions on how land owner and members share risk. For example, members experienced the driest season since the establishment of the gardens in 2012, with no rain for six months and warm winds contributing to worsening soil conditions. At the same time, water supply for irrigation was very inconsistent.

A third and final sub-typology of self-consumption community garden entails network governance: these AFNs do not present legal contracts and are based on trust among members to participate and manage the group operations. Moreover, some of the initiatives pertaining to this sub-category present their own statutes and standards jointly created by the members to ensure garden prosperity and group functioning. In this case, consumers and producers blend in taking decision-making responsibilities since the actors involved are citizens that usually perform both roles. Members share common objectives to support social and environmental transitions by strengthening social cohesion, recovery of degraded urban land and provision of an educational and interactive space. These network-based community gardens for self-consumption are based on a form of self-organization: members themselves, through informal conversations, decision-making processes and emerging routines, decide how to govern. In some cases, a voluntary group of people took responsibility to establish informal rules for the other participants, in agreement with the rest of the group. The self-organizing nature of this typology of community gardens creates, first of all, issues in organizing procurement of resources. The provision of fundamental resources is at times improvised. In one AFN, members brought and planted the seedlings they had available without planning across the garden, while one member voluntarily installed water pipes for drip irrigation. Also composting was reliant on few members producing it. This improvisation creates a sense of reciprocity among members, yet also some uncertainty on the conditions and inputs necessary to grow the garden. Since participation is strongly fuelled by self-motivation and members' alignment in goals, when members experience drops in energy and enthusiasm the entire garden organization is at risk of collapse. Finally, these network-based community gardens often experience conflicts arising on the land access and excludability rights with external parties. Since there is no formal documentation guaranteeing exclusive use of the land by the public administration, some AFNs experience issues with external people accessing the land.

\section{Implications for theory development}

This research aims to compare and systematically characterise AFNs as sharing economy initiatives in the agri-food sector in terms of which and how resources are shared. By taking such an organization theory perspective and applying it to the case of AFNs in the urban and peri-urban area of Valencia, this study sheds light on the heterogeneity of sharing economy initiatives in the agri-food sector. Understanding this organizational heterogeneity, and associating it with their origins and constraints, helps to further articulate the debate on the governance, effects and risks of sharing economy. In particular, these insights nuance the debate on the sharing economy beyond an antagonism between enthusiasts and critics towards a reflection on which organizational 
models may be more or less suitable given the goals, history and resources at hand of their members.

In terms of which resources are shared, findings confirm that participants in AFNs shared heterogeneous resources at different stages of the process linking production and consumption activities. Some AFNs focused on sharing resources only at specific stages of the food value chain. For example, consumer groups are unique in sharing storage/ distribution space and technology only during their food procurement and consumption stages. Furthermore, selfconsumption community gardens focused on sharing all the resources needed to participants at the production stage, including the distribution of the needed agricultural inputs. Conversely, commercial community gardens required participants to share resources over a larger span of activities, from production to distribution and marketing. To some extent, the goals and history of these AFNs relates to and may explain this resource-sharing. AFNs that focus their resource-sharing only in storage/distribution (consumer groups) or in production (self-consumption community gardens) emerged mostly from social initiatives and movements, thus with non-market goals such as environmental sustainability, community development or poverty eradication. As such, members are mostly engaged in focusing their shared resources in few activities. Conversely, AFNs that broaden their resource-sharing to multiple stages of production, distribution and storage (commercial community gardens) emerge with a dual commercial purpose, linking two parties (i.e., landowners and a community of land renters) seeking also a market advantage from this transaction. In this case, members engage in a more complex and heterogeneous range of activities with a stronger expectation of gaining a market return than in other AFNs.

From a theoretical standpoint, this analysis on which resources are shared tells us that it may be appropriate to explain the emergence and establishment of sharing economy models based on which resources are shared (funds, labour/time, space, equipment at different stages of a value chain) along with who their members are (consumers versus producers; Cohen and Muñoz 2016) or what they want (Barnes and Mattsson 2016). This distinction demonstrates that the sharing economy cut across the stereotypical distinction between producers and consumers, as consumers engage in sharing resources for production and vice versa. Moreover, sharing economy models cut also across the distinction between market value versus social value creation; instead, members in different AFNs invest resources to different ranges of activities with corresponding expectations of market returns. Looking specifically at the agri-food sector, this distinction may help with characterizing the differences and the evolution of AFNs Indeed, typologies of AFNs such as CSAs, AMAPs and SPGs, even professing similar goals and motivations (Renting et al. 2003; Hatano
2008; Tregear 2011; Cembalo et al. 2015), may engage in significantly different models of resource-sharing, with consequences on their members' participation and welfare.

In terms of how resources are shared, findings confirm that informal mechanisms prevail in the governance of sharing economy organizations (Lagane 2015). In most of the sampled AFNs, although to different extents, communitarian elements of trust and reciprocity grounded on common values are used as mechanisms to regulate the resource-sharing. Yet, some AFNs (i.e., self-consumption community gardens initiative by private owners and the municipality) have more bureaucratic elements (i.e. formal laws, procedures, committees) than others in regulating the sharing process. Importantly, the presence of these bureaucratic elements seems to relate to the specific origins and size of their organizations. First, members in hybrid AFNs (i.e. with some bureaucratic elements blended with communitarian ones) have not chosen each other in pursuing community garden activities. Instead, they have entered into a membership based on a bilateral linkage with the leader of the initiative (i.e. respectively the municipality and the landowner). Second, perhaps given these origins or the stage of evolution of these AFNs, these hybrid models entail a larger number of participants which are harder to regulate only based on trust and reciprocity principles. Conversely, network-based models (i.e., with low or no presence of bureaucracy) such as consumer groups and commercial community gardens seem to be moved mostly by community development, political and environmental goals. These initiatives usually originate from smaller, selforganized groups of individuals sharing the same values and motivations already before the start of the AFNs, and pooling their time and skills (in addition to other resources) to attract other participants to the AFNs. Perhaps not surprisingly, then, AFNs with different levels of bureaucracy, shared resources and origins also face different organizational barriers. On the one hand, AFNs with participants not bound in pre-existing networks or through common values often face issues of conflicting motivations among members, limited active engagement and lack of coordination. On the other hand, AFNs based on pre-existing networks and common values have to address issues of limited time and resources, as well as difficulties in attracting new members and changing consumption habits.

Disentangling on how resources are shared from an organization standpoint contributes to the literature on AFNs and, beyond the agricultural and food sector, on the organization of sharing economy models. So far only few studies focused on the internal organization of AFNs (Murtagh 2010; Albrecht et al. 2016), while mostly focusing on external linkages of AFNs with implications for society and regional development (Holloway et al. 2007; Tregear 2011; Veen et al. 2012). The strong or even exclusive presence of communitarian elements 
in some AFNs show similarities with SPGs and AMAP initiatives in other contexts (Dubuisson-Quellier et al. 2011; Pascucci et al. 2013, 2016), and explain their organization based on their origin and/or relatively small number of members. Looking beyond the agricultural and food sector, the pattern linking smaller-size and communitarian AFNs may explain why participants in large sharing economy models may prefer formal regulatory procedures (Hartl et al. 2016) or feel excluded when these formal elements are missing (Schor et al. 2016). As such, this organization lens helps positioning AFNs within the broader spectrum of sharing economy models (Lamberton and Rose 2012; Botsman 2013; Gansky 2014; Smith 2014). First of all, the cases of Valencia confirm that AFNs reflect a narrower meaning of sharing - meant as informal co-access rather than co-ownership of tangible resource (Belk 2007)—relative to Botsman (2013). Furthermore, AFNs in Valencia feature a broader distribution of power among members: when the number of AFNs' members grow, then bureaucratic elements are often developed to maintain such a broad power distribution. Therefore, these results seem to suggest that AFNs as sharing economy models in today's agricultural and food sector are less subject to negative implications such as labour rights reduction (Richardson 2015), subtle reproduction of social exclusion (Schor 2014) and corporate co-optation (Martin 2016).

\section{Recommendations for policy-makers and leaders in alternative food networks}

This empirical analysis on which and how resources are shared in AFNs leads to recommendations to policy-makers, AFN members and their stakeholders that, through the choice or blending of communitarian and bureaucratic elements, may influence their future evolution and diffusion. Of course, these recommendations need to take into account the limitations of this empirical study, that is, its context specificity and the limited exploration of networks outside and across AFNs.

While AFNs are emerging and establishing as phenomenon in urban and peri-urban areas, the lack of integration of these activities in a policy framework may constitute a significant constraint for their development of appropriate bureaucratic elements as they grow in size and number. Some community gardens, for example, occupy degraded urban land to start their initiatives. Insecure property rights and back-door strategies for accessing land can lead to long struggles and conflicts between landowners (generally banks and/or construction companies) and AFN members, and even among participants as the AFNs grow. While the EU is taking measures to regulate the sharing economy organizations with commercial purposes (e.g., introducing and adapting legislation to the context of rapidly growing enterprises such as Zipcar and Airbnb), the regulation on
AFNs as smaller-scale and local forms of sharing economy remain below policy sightline. It might be a strategic point for policy-makers at EU, national and local levels to regulate and/or support AFNs through legislation that recognizes the right of citizens to access and formally regulate unused and degraded land with the purpose of food production. Yet, the wide heterogeneity of AFNs' organizational forms and goals challenges the development of legislation for AFNs. Given this heterogeneity, it is advisable that policy-makers design a tailored approach in defining this formal regulation. For example, policy-makers may support the development of participatory platforms or communities of practice (Waddell et al. 2013) that facilitate policy changes with the involvement of the civil society at multiple levels (Waddell et al. 2015), as the experience of Agenda 21 has demonstrated also in the case of Valencia (PAT 2014).

Furthermore, the findings of this research draw upon recommendations for participants involved in AFNs' activities, as well as external stakeholders seeking to support AFNs' organizational learning and change processes. Overall, participants in AFNs should strengthen inter-group learning and cross-group network building similar to what Beckie et al. (2012) found in the case of Canada. This would stimulate knowledge flows among groups with similar goals to share suitable organizational practices and solutions against common constraints. For example, findings show that different AFNs (e.g. commercial community gardens and consumer groups) may find strong resource and organizational complementarities with each other. Last, there is great need to inform citizens on the extent to which AFNs contribute in supporting local economies, sustainable food practices and community building. Ideally, current AFN participants may be best positioned to create these inter-group networks tailored to the needs of their AFNs. Yet, given the time and resource scarcity faced by many AFNs, universities (Dentoni and Bitzer 2015) and other knowledge brokers (Dicecca et al. 2016) may play critical roles as intermediaries among multiple AFNs or between AFNs and governments at multiple levels.

Open Access This article is distributed under the terms of the Creative Commons Attribution 4.0 International License (http:// creativecommons.org/licenses/by/4.0/), which permits unrestricted use, distribution, and reproduction in any medium, provided you give appropriate credit to the original author(s) and the source, provide a link to the Creative Commons license, and indicate if changes were made.

\section{Appendix: Variables meaning and coding}

See Table 3. 


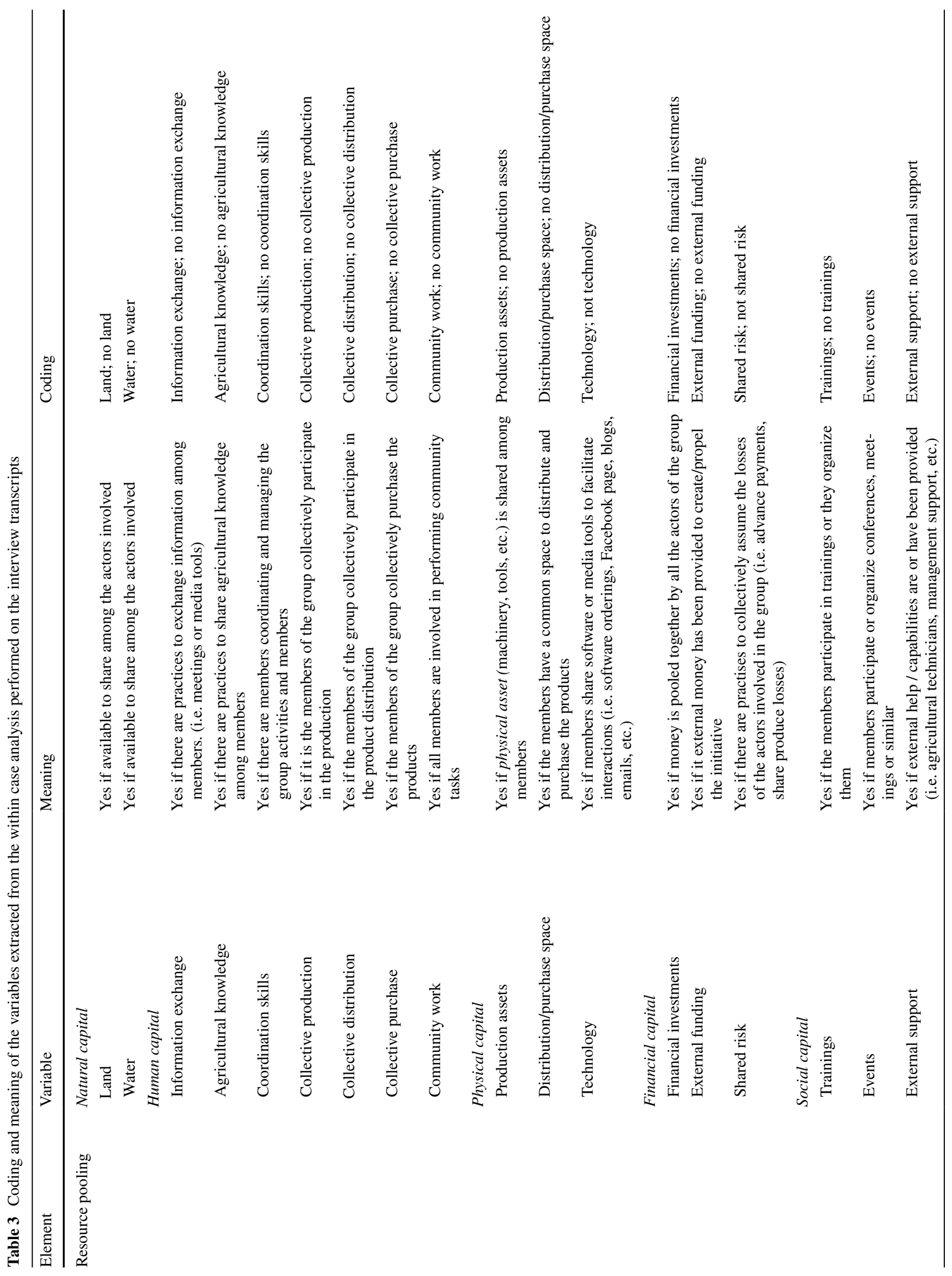




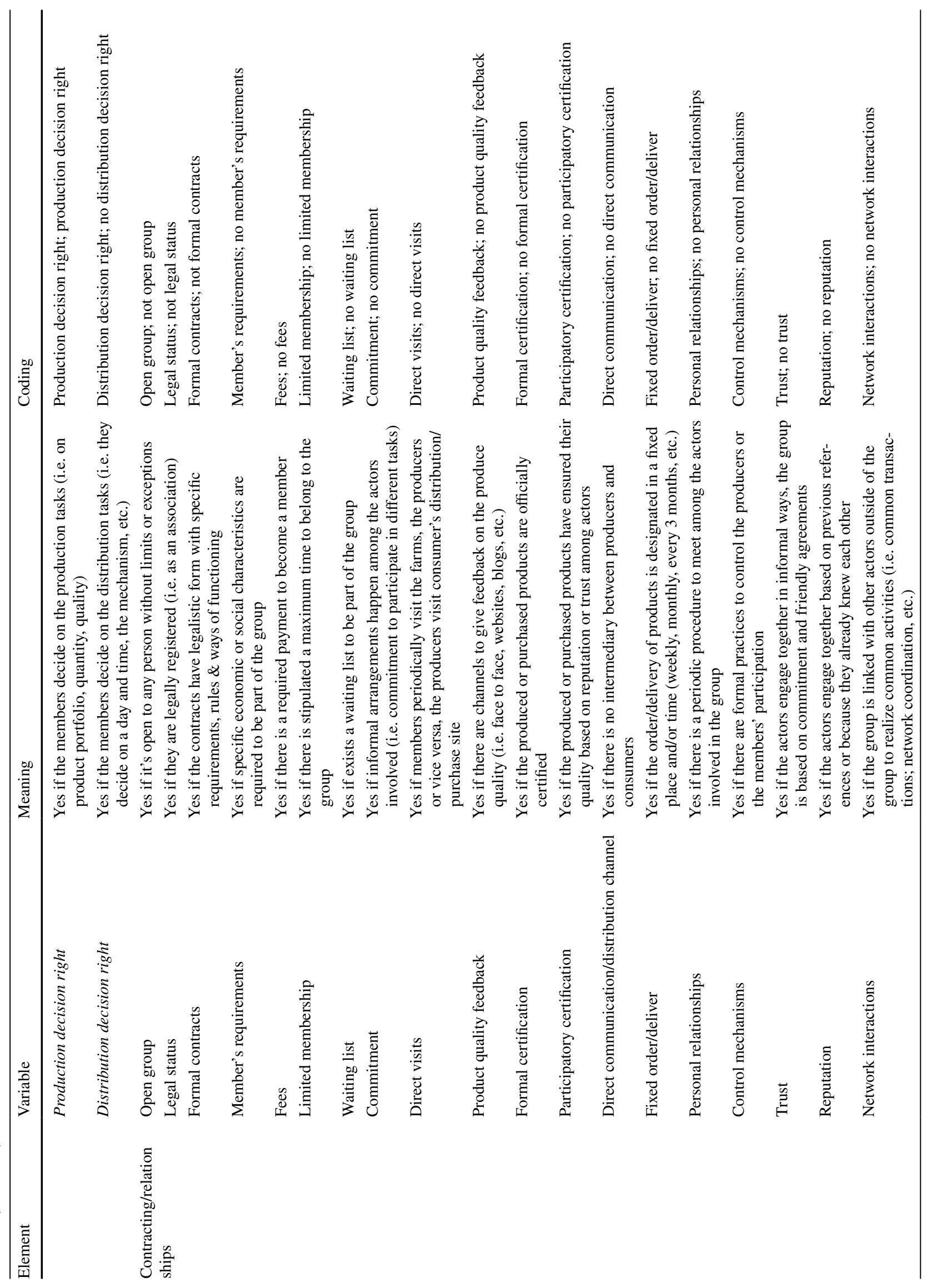




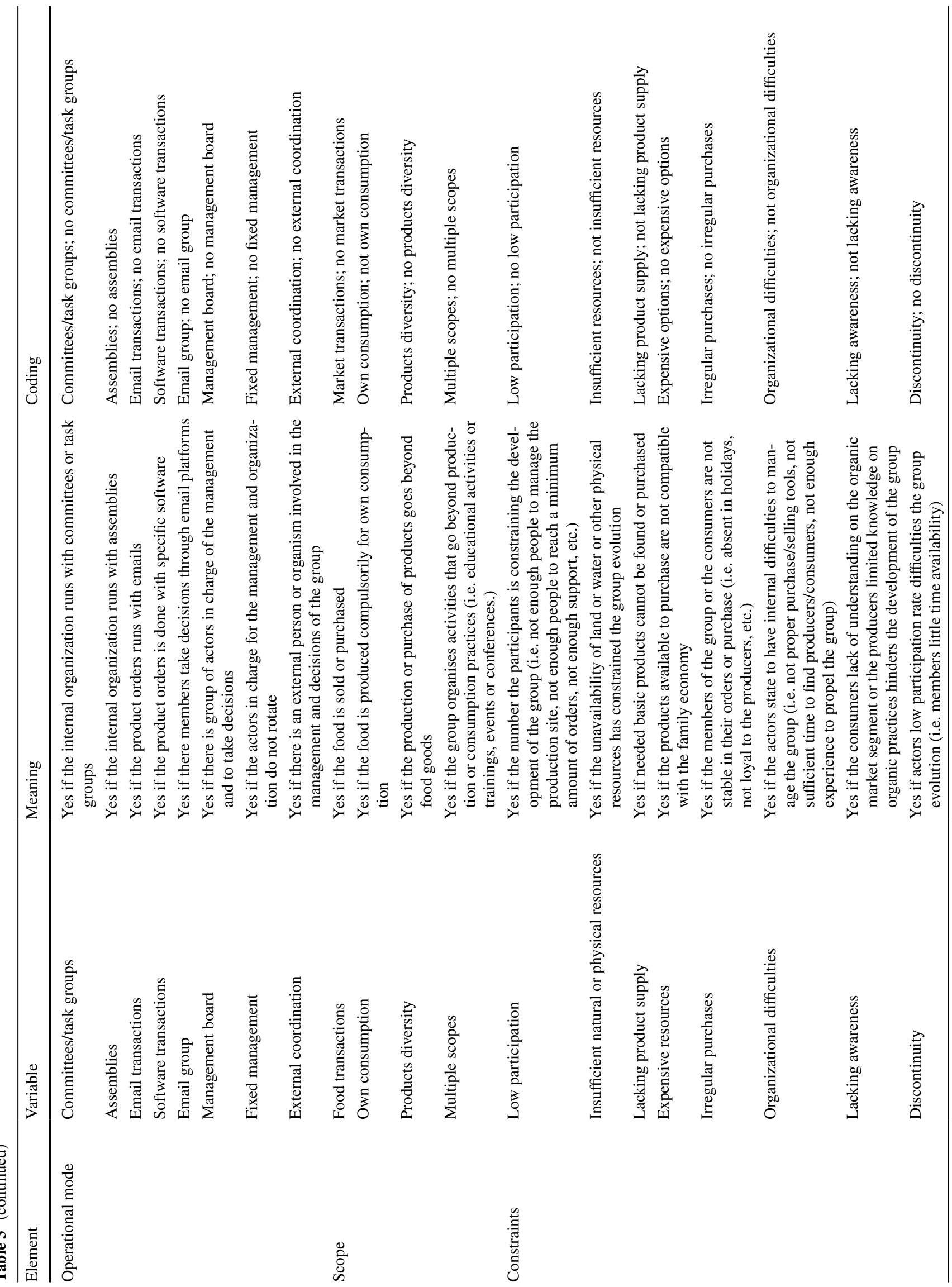




\section{References}

Adler, P. S. 2001. Market, hierarchy, and trust: The knowledge economy and the future of capitalism. Organization Science 12(2):215-234.

Adler, P. S., and C. C. Heckscher., eds. 2006. The firm as a collaborative community: Reconstructing trust in the knowledge economy. 11-105. Oxford: Oxford University Press.

Albrecht, C., R. Johnson, S. Hamann, L. Ohberg, and M. CoDyre. 2016. Toward alternative food systems development: exploring limitations and research opportunities. Journal of Agriculture, Food Systems, and Community Development 3(4):151-159.

AMAP. 2014. National Directory of AMAP. http://www.reseau-amap. org. Accessed 15 January 2016.

Bardhi, F., and Eckhardt, G. M. 2012. Access-based consumption: The case of car sharing. Journal of Consumer Research 39(4):881-898.

Barnes, S.J., and J. Mattsson. 2016. Understanding current and future issues in collaborative consumption: a four-stage Delphi study. Technological Forecasting and Social Change 104:200-211.

Beckie, M. A., Kennedy, E. H., and Wittman, H. 2012. Scaling up alternative food networks: Farmers' markets and the role of clustering in western Canada. Agriculture and Human Values 29(3):333-345.

Belk, R. 2007. Why not share rather than own? The Annals of the American Academy of Political and Social Science 611(1):126-140.

Belk, R. 2010. Sharing. Journal of Consumer Research 36(5):715-734.

Belk, R. 2013. You are what you can access: Sharing and collaborative consumption online. Journal of Business Research 67(8):1595-1600.

Bloemmen, M., R. Bobulescu, N.T. Le, and Vitari, C. 2015. Microeconomic degrowth: The case of Community Supported Agriculture. Ecological Economics 112:110-115.

Borge-Holthoefer, J., González-Bailón, S., Rivero, A., and Moreno, Y. 2014. The Spanish "Indignados" movement: Time dynamics, geographical distribution, and recruitment mechanisms. In Online Collective Action. 155-177. Vienna: Springer.

Botsman, R. 2013. The Sharing Economy Lacks A Shared Definition. http://www.fastcoexist.com/3022028/the-sharing-economylacks-a-shared-definition. Accessed 7 January 2016.

Botsman, R., and R. Rogers. 2010. Beyond zipcar: collaborative consumption. Harvard Business Review 88(10):30.

Bowles, S., and Gintis, H. 2002. Social capital and community governance. The Economic Journal 112(483):419-436.

Brunori, G., Rossi, A., and Guidi, F. 2012. On the new social relations around and beyond food. Analysing consumers' role and action in Gruppi di Acquisto Solidale (solidarity purchasing groups). Sociologia Ruralis 52(1):1-30.

Business Innovation Observatory. 2013. European Union (EU) Business innovation observatory. http://ec.europa.eu/growth/industry/ innovation/business-innovation-observatory. Accessed 23 Oct 2016.

Cembalo, L., Lombardi, A., Pascucci, S., Dentoni, D., Migliore, G., Verneau, F., and Schifani, G. 2015. "Rationally Local": Consumer participation in alternative food chains. Agribusiness: an International Journal 31(3):330-352.

Chiffoleau, Y. 2009. From politics to co-operation: The dynamics of embeddedness in alternative food supply chains. Sociologia ruralis 49(3):218-235.

Cicia, G., Colantuoni, F., Teresa, D. G., and Pascucci, S. 2011. Community Supported Agriculture in the Urban Fringe: Empirical evidence for project feasibility in the Metropolitan Area of 
Naples (Italy). International Journal on Food System Dynamics 2 (3):326-339.

Cohen, B., and P. Muñoz. 2016. Sharing cities and sustainable consumption and production: towards an integrated framework. Journal of Cleaner Production 134:87-97.

Collaborative Economy Coalition. 2014. http://www.collaborativeeconomycoalition.org/what-is-the-collaborative-economy/. Accessed 18 January 2016.

Colombo, L.A. 2012. AICCON Ricerca. The Gruppi di Acquisto Solidale as laboratories of civil economy. http://www.aiccon.it/ ricerca_scheda.cfm?wid=297\&archivio=C. Accessed 1 February 2016.

Contreras, J., and T. Snir. 2011. MIT Sloan grad on the "sharing economy", the next big trend in social commerce". http://mitsloanexperts.mit.edu/mit-sloan-grad-on-the-sharing-economy-thenext-big-trend-in-social-commerce/\#sthash.NFvDJqhm.dpuf. Accessed 11 January 2016.

Del Corso, J. P., Kephaliacos, C., and Plumecocq, G. 2015. Legitimizing farmers' new knowledge, learning and practices through communicative action: Application of an agro-environmental policy. Ecological Economics 117:86-96.

Dentoni, D., and Bitzer, V. 2015. The role(s) of universities in dealing with global wicked problems through multi-stakeholder initiatives. Journal of Cleaner Production 106:68-78.

Dicecca, R., Pascucci, S., and Contò, F. 2016. Understanding reconfiguration pathways of agri-food value chains for smallholder farmers. British Food Journal 118(8):1857-1882.

Dubuisson-Quellier, S., Lamine, C., and Le Velly, R. 2011. Citizenship and consumption: Mobilisation in alternative food systems in France. Sociologia Ruralis 51(3):304-323.

Eisenhardt, K. M. 1989. Building theories from case study research. Academy of Management Review 14(4):532-550.

European Sharing economy Coalition. 2013. http://www.euro-freelancers.eu/european-sharing-economy-coalition/. Accessed 4 January 2016.

FAO. 2007. Food and Agriculture Organization of the United Nations. The urban producer's resource book: A practical guide for working with Low Income Urban and Peri-Urban Producers Organizations. ftp://ftp.fao.org/docrep/fao/010/a1177e/a1177e.pdf. Accessed 11 November 2016.

Forssell, S., and Lankoski, L. 2015. The sustainability promise of alternative food networks: an examination through "alternative" characteristics. Agriculture and Human Values 32(1):63-75.

Gansky, L. 2011. Online source available at: "Why the future of the business is the mesh". https://www.ted.com/talks/lisa_gansky_the_future_of_business_is_the_mesh. Accessed 16 January 2016.

Gansky, L. 2014. 5 Signs that the collaborative economy is going through puberty. http://www.fastcoexist.com/3030564/5-signsthat-the-collaborative-economy-is-going-through-puberty. Accessed 4 January 2016.

Gaskins, K., and N. Stehfest. 2010. Latitude Research and Shareable Magazine. http://latdsurvey.net/pdf/Sharing.pdf. Accessed 5 January 2016.

Gioia, D. A., Corley, K. G., and Hamilton, A. L. 2013. Seeking qualitative rigor in inductive research notes on the Gioia methodology. Organizational Research Methods 16(1):15-31.

Goodman, D., and Goodman, M. 2009. Alternative food networks. International Encyclopedia of Human Geography. 208-220. Oxford: Elsevier.

Grandori, A. 1997. An organizational assessment of interfirm coordination modes. Organization Studies 18(6):897-925.

Grandori, A., and Furnari, S. 2008. A chemistry of organization: Combinatory analysis and design. Organization Studies 29(3):459-485.
Grasseni, C. 2014. Seeds of trust. Italy's Gruppi di Acquisto Solidale (Solidarity Purchase Groups). Journal of Political Ecology 21:178-192.

Gruszka, K. 2016. Framing the collaborative economy-voices of contestation. Environmental Innovation and Societal Transitions. in press.

Hartl, B., Hofmann, E., and Kirchler, E. 2016. Do we need rules for "what's mine is yours"? Governance in collaborative consumption communities. Journal of Business Research 69(8):2756-2763.

Hatano, T. 2008. The Organic Agriculture Movement (Teikei) and factors leading to its decline in Japan. Journal of Rural and Food Economics 54 (2): 21-34

Heinrichs, H. 2013. Sharing economy: a potential new pathway to sustainability. Gaia 22(4):228.

Henderson, E., and Van En, R. 2007. Sharing the harvest: A citizen's guide to community supported agriculture, revised and expanded. White River Junction: Chelsea Green Publishing.

Holloway, L., Kneafsey, M., Venn, L., Cox, R., Dowler, E., and Tuomainen, H. 2007. Possible food economies: a methodological framework for exploring food production-consumption relationships. Sociologia Ruralis 47(1):1-19.

Husson, F., J. Josse, and J. Pages. 2010. Principal component methods-hierarchical clustering-partitional clustering: why would we need to choose for visualizing data. Applied Mathematics Department: Technical Report-Agrocampus.

Husson, F., J. Josse, S. Le, and Mazet, J. 2013. FactoMineR: multivariate exploratory data analysis and data mining with R. $R$ package version 1:102-123.

John, N. A. 2013. The social logics of sharing. The Communication Review 16(3):113-131.

Jones, C., Hesterly, W. S., and Borgatti, S. P. 1997. A general theory of network governance: Exchange conditions and social mechanisms. Academy of Management Review 22(4):911-945.

Jurich, L. 2013. Why this CEO doesn't own a car: The rise of disownership. http://www.fastcoexist.com/1681112/why-this-ceodoesnt-own-a-car-the-rise-of-dis-ownership. Accessed 4 January 2016.

Lagane, J. 2015. When students run AMAPs: towards a French model of CSA. Agriculture and Human Values 32(1):133-141.

Lamberton, C. P., and Rose, R. L. 2012. When is ours better than mine? A framework for understanding and altering participation in commercial sharing systems. Journal of Marketing 76(4):109-125.

Llamas-Sanchez, R., Garcia-Morales, V., and Martin-Tapia, I. 2013. Factors affecting institutional change: a study of the adoption of Local Agenda 21 in Spain. Journal of Organizational Change Management 26(6):1045-1070.

Lockie, S. 2009. Responsibility and agency within alternative food networks: assembling the "citizen consumer". Agriculture and Human Values 26(3):193-201.

Martin, C.J. 2016. The sharing economy: A pathway to sustainability or a nightmarish form of neoliberal capitalism? Ecological Economics 121:149-159.

Martin, C.J., P. Upham, and L. Budd. 2015. Commercial orientation in grassroots social innovation: insights from the sharing economy. Ecological Economics 118:240-251.

McLaren, D., and J. Agyeman. 2015. Sharing cities: a case for truly smart and sustainable cities. MIT Press.

Ménard, C. 1996. The economics of hybrid organizations. Journal of Institutional and Theoretical Economics 160(3):1-32.

Ménard, C. 2004. The economics of hybrid organizations. Journal of Institutional and Theoretical Economics JITE 160(3):345-376.

Ménard, C. 2005. A new institutional approach to organization. In Handbook of new institutional economics, 281-318. Dordrecht: Springer. 
Ménard, C. 2007. Cooperatives: Hierarchies or hybrids? In Vertical markets and cooperative hierarchies, 1-18. Dordrecht: Springer.

Migliore, G., Schifani, G., Guccione, G. D., and Cembalo, L. 2014. Food community networks as leverage for social embeddedness. Journal of Agricultural and Environmental Ethics 27 (4): 549-567.

Migliore, G., Schifani, G., Romeo, P., Hashem, S., and Cembalo, L. 2015. Are farmers in alternative food networks social entrepreneurs? Evidence from a behavioral approach. Journal of Agricultural and Environmental Ethics 28 (5): 885-902.

Mount, P. 2012. Growing local food: scale and local food systems governance. Agriculture and Human Values 29 (1): 107-121.

Murtagh, A. 2010. A quiet revolution? Beneath the surface of Ireland's alternative food initiatives. Irish Geography 43 (2): $149-159$.

Orsi, J. (2013). The sharing economy just got real. http://www.shareable.net/blog/the-sharing-economy-just-got-real. Accessed 5 January 2016.

O'Mahony, S., and Ferraro, F. 2007. The emergence of governance in an open source community. Academy of Management Journal 50(5):1079-1106

PAT. 2014. Plan de Acción Territorial de Protección de la Huerta de Valencia. Conselleria de Medio Ambiente, agua, urbanismo y vivienda. Generalitat valenciana. http://www.cma.gva.es. Accessed 4 January 2016.

Pascucci, S. 2010. Governance structure, perception, and innovation in credence food transactions: The role of food community networks. International Journal on Food System Dynamics 1(3):224-236.

Pascucci, S., Lombardi, A., Cembalo, L., and Dentoni, D. 2013. Governance mechanisms in food community networks. Italian Journal of Food Science 25(1):98-104.

Pascucci, S., Dentoni, D., Lombardi, A., and Cembalo, L. 2016. Sharing values or sharing costs? Understanding consumers' participation in alternative food networks. NJAS Wageningen Journal of Life Sciences 78:47-60.

Renting, H., Marsden, T. K., and Banks, J. 2003. Understanding alternative food networks: exploring the role of short food supply chains in rural development. Environment and Planning A 35(3):393-412.

Richardson, L. 2015. Performing the sharing economy. Geoforum 67:121-129.

Sacks, D. 2011. The Sharing Economy. http://www.fastcompany. com/1747551/sharing-economy. Accessed 4 January 2016

Schnell, S. M. 2007. Food with a farmers' face: Community-supported Agriculture in the United States. Geographical Review 97(4):550-564.

Schor, J.B. 2014. Debating the sharing economy. http://www.greattransition.org/publication/debating-the-sharing-economy. Accessed 23 Oct 2016.

Schor, J.B., C. Fitzmaurice, L.B. Carfagna, W. Attwood-Charles, and E.D. Poteat. 2016. Paradoxes of openness and distinction in the sharing economy. Poetics 54:66-81.

Si, Z., Schumilas, T., and Scott, S. 2015. Characterizing alternative food networks in China. Agriculture and Human Values 32(2):299-313.

Smith, S. 2014. Is this really the sharing economy? http://videos. liftconference.com/video/9491052/scott-smith-is-this-really-thesharing. Accessed 4 January 2016.

Standage, T. 2013. The rise of the sharing economy. http://www.economist.com/news/leaders/21573104-internet-everything-hire-risesharing-economy. Accessed 5 January 2016.
Sunrun. 2013. New Survey Reveals "Disownership" is the New Normal. http://www.sunrun.com/why-sunrun/about/news/pressreleases/new-survey-reveals-disownership-is-the-new-normal/. Accessed 3 January 2016.

Tregear, A. 2011. Progressing knowledge in alternative and local food networks: Critical reflections and a research agenda. Journal of Rural Studies 27(4):419-430.

Urgenci. 2013. The International Network of Community Supported Agriculture. http://urgenci.net/en-gb. Accessed 8 January 2016.

Veen, E. J., Derkzen, P., Wiskerke, J. S., and Renting, H. 2012. Motivations, reflexivity and food provisioning in alternative food networks: case studies in two medium-sized towns in the Netherlands. International Journal of Sociology of Agriculture and Food 19(3):365-382.

Waddell, S., McLachlan, M., and Dentoni, D. 2013. Learning \& transformative networks to address wicked problems: A GOLDEN Invitation. International Food and Agribusiness Management Review 16(A):23-32.

Waddell, S., Waddock, S., Cornell, S., Dentoni, D., McLachlan, M., and Meszoely, G. 2015. Large systems change: an emerging field of transformation and transitions. The Journal of Corporate Citizenship 58:5-31.

Williamson, O. E. 2002. The theory of the firm as governance structure: from choice to contract. Journal of Economic Perspectives 16(3):171-195.

Wubben, E.F.M., Fondse, M., and Pascucci, S. 2013. The importance of stakeholder-initiatives for business models in short food supply chains: the case of the Netherlands. Journal on Chain and Network Science 13(2):139-149.

Yin, R. K. 2009. Case study research: Design and methods. London: Sage Publications Ltd.

Isabel Miralles is a Master of Science (MSc) graduate in food technology at Wageningen University (The Netherlands). She has recently worked with food accreditation and organic certification companies in Wellington (New Zealand). As a researcher and activist, she has a passion in understanding the dynamics of power and trade relationships in food supply chains.

Domenico Dentoni Ph.D., is associate professor at the Management Studies Group, Department of Social Sciences, Wageningen University (The Netherlands) and principal investigator of the Global Center for Food Systems Innovation (GCFSI). With funding support from European Union, Australian, Dutch and US governments, his team research addresses the question on how organizations recombine resources - internally and externally to their boundaries - to deal with complex societal problems in agri-food systems.

Stefano Pascucci Ph.D., is professor in Sustainability and Circular Economy at the University of Exeter Business School (UK), and visiting researcher Department of Social Sciences, Wageningen University (The Netherlands). He is an applied economist who developed an interest for sustainability as connected to organization theories, innovation management, and value chain analysis. His research focuses on agribusiness, sustainability and circular economy. He is particularly concerned about how to analyse the interplay between sustainability, collaborative (open) innovation and value chain configurations. 